\title{
Laparoscopic approach to distal pancreatectomy in pancreatic cystic neoplasms - report of three cases and literature review
}

\author{
Andrzej P. Kwiatkowski, Piotr K. Kowalewski, Krzysztof Paśnik \\ Department of General, Oncological, Metabolic and Thoracic Surgery, Military Institute of Medicine, Warsaw, Poland
}

Videosurgery Miniinv 2015; 10 (3): 499-503

DOI: $10.5114 /$ wiitm.2015.54058

\begin{abstract}
The development of cross-section imaging increased the number of diagnosed pancreatic cystic neoplasms (PCNs). Many of these lesions, located frequently in the body or tail of the organ, require resection. We present three cases of patients undergoing laparoscopic distal pancreatectomy because of PCNs, describing the technique along with the post-operative course. The reviewed literature confirms the benefits of the laparoscopic approach, yet it lacks randomized, controlled trials. We also present two spleen-preserving surgical techniques - with and without ligation of the splenic vessels. Both of these procedures can be performed with laparoscopy or laparotomy, but there is no consensus which should be the method of choice.
\end{abstract}

Key words: laparoscopic surgery, pancreas, distal pancreatectomy, cystic neoplasm, spleen-preserving.

\section{Introduction}

Pancreatic cystic non-inflammatory tumors comprise $50-60 \%$ of all cystic tumors of the organ. The widespread availability of cross-section imaging increases the number of diagnosed lesions [1]. The basic categorization divides pancreatic cystic neoplasms (PCNs) into non-neoplastic and neoplastic, out of which the second group have a malignant potential that requires resection. This particular feature emphasizes the need for precise evaluation of lesions. The non-neoplastic PCNs demand endoscopic or surgical attention only when presenting symptoms.

\section{Aim}

The aim of this article is to present a series of cases of 3 patients with symptomatic pancreatic cysts, who underwent minimally invasive, laparoscopic distal pancreatectomy.

\section{Case reports}

The first patient was a 31-year-old woman with epigastric pain and bloating. Abdominal ultrasound revealed a $70 \times 42 \mathrm{~mm}$ cystic lesion in the tail of the pancreas, diagnosed with computed tomography (CT) as a cystadenoma. The patient was disqualified from endoscopic ultrasound (EUS) and therefore underwent a surgical laparoscopic biopsy. Histopathological examination defined the lesion as a mucinous cystic neoplasm with low grade dysplasia. Therefore the patient was qualified for distal pancreatectomy. Laparoscopic surgery was performed with five trocars: one $12 \mathrm{~mm}$, three $10 \mathrm{~mm}$ and one $5 \mathrm{~mm}$ (Figure 1). The peritoneal cavity was insufflated with carbon dioxide with a Veress needle, introduced in the left flank, up to $12 \mathrm{~mm} \mathrm{Hg}$. The peritoneal cavity was inspected. The omental bursa was opened through the gastrocolic ligament, along the stomach's greater curvature, with ultrasonic scissors (SonoSurg,

\section{Address for correspondence}

Piotr K. Kowalewski, Department of General, Oncological, Metabolic and Thoracic Surgery, Military Institute of Medicine, 6/40 Wolumen St, 01-912 Warsaw, Poland, phone: +48 504445 800, e-mail: pietia.kowalewski@gmail.com 


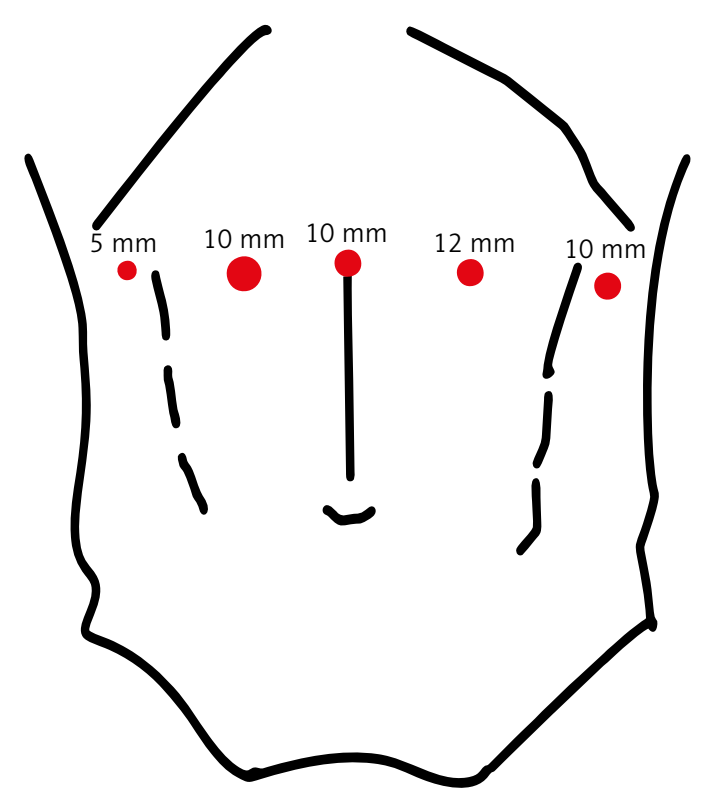

Figure 1. Placement of trocars

Olympus). The tail of the pancreas was dissected, from its bottom edge, behind the body, and reaching the splenic vessels, which were bluntly pushed away from the posterior pancreatic wall. Small pancreatic veins and arteries were clipped with titanium clips. The tail was then separated from the body with a $60 \mathrm{~mm}$ EndoGIA stapler (EndoGIA 60, purple cartridge, Covidien) and retrieved via Pfannenstiel's suprapubic incision (Photos 1 and 2). The body of the pancreas was then secured with braided, nonabsorbable, single sutures (Photo 3 ). The procedure lasted $210 \mathrm{~min}$. Enteral nutrition was introduced on day 1 . No sign of pancreatic fistula was noted. The patient was discharged on day 6 .

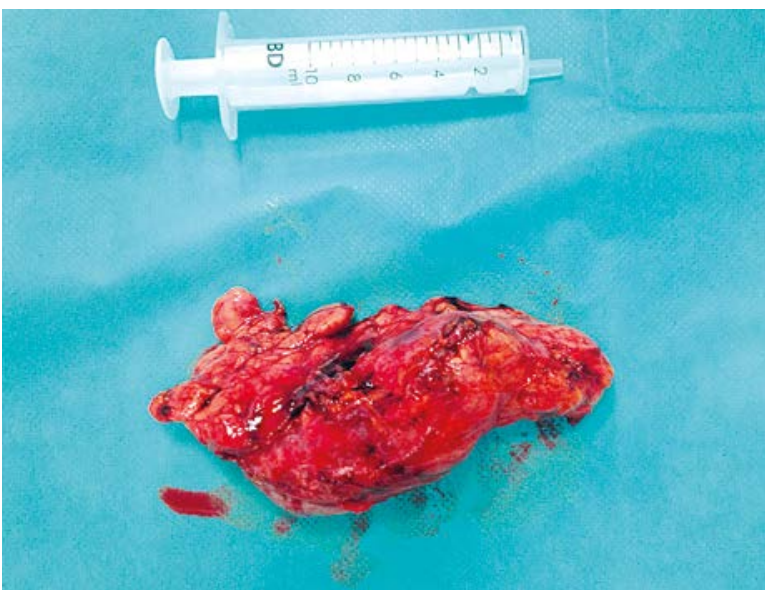

Photo 2. Post-op. specimen - tail of pancreas

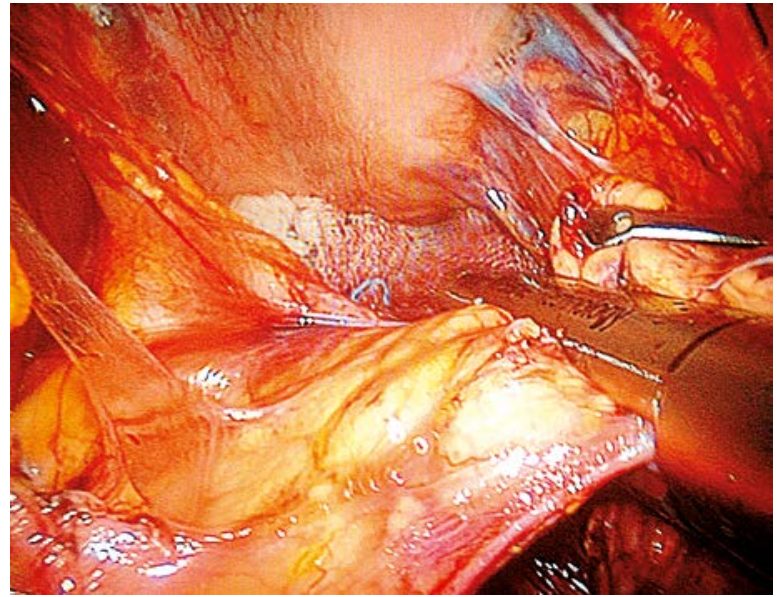

Photo 1. Tail of pancreas stapled with $60 \mathrm{~mm}$ EndoGIA stapler

The second patient was a 54-year-old asymptomatic woman with a history of hypertension and three c-sections. The lesion, a $19 \times 18 \mathrm{~mm}$ tumor located in the tail, was incidentally found during abdominal ultrasound - followed by a CT scan. The patient underwent a laparoscopic procedure technically similar to the first patient. The procedure lasted 225 min. There were no symptoms of pancreatic fistula. The patient was discharged on day 5 . Histological examination described the lesion as an acinar pancreatic cystadenoma.

The third patient was a 57-year-old woman with epigastric pain, a history of chronic obstructive pulmonary disease and a c-section. Abdominal CT scan showed a partially cystic, $30 \times 26 \times 26$ tumor, located in the tail of the pancreas, in close proximity to the splenic vessels. The laparoscopy was performed with

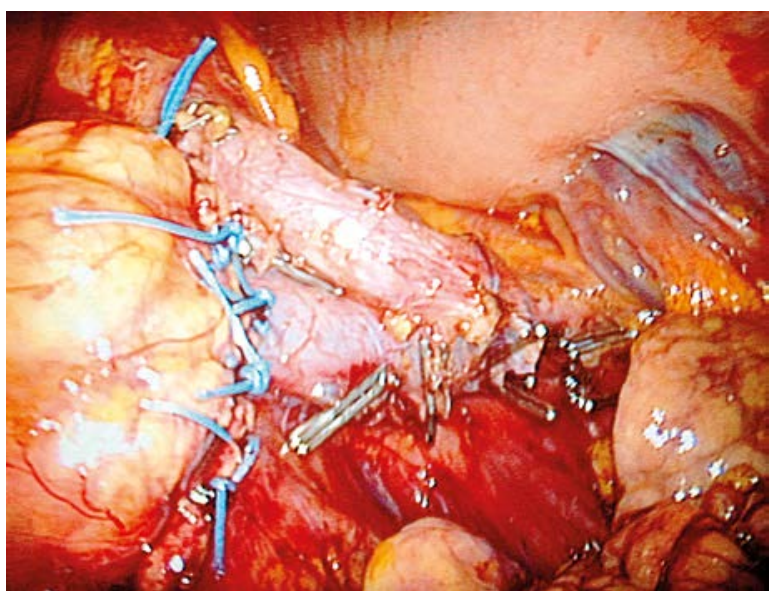

Photo 3. Body of pancreas and splenic vessels 
Table I. Patient details

\begin{tabular}{|llccc|}
\hline No. & Gender & Age [years] & Symptoms & Tumor size [mm] \\
\hline 1 & Female & 31 & Epigastric pain & $70 \times 42$ \\
\hline 2 & Female & 54 & None (incidentaloma) & $19 \times 18$ \\
\hline 3 & Female & 57 & Epigastric pain & $30 \times 26$ \\
\hline
\end{tabular}

Table II. Procedure details and outcomes

\begin{tabular}{|lcccccc|}
\hline No. & Procedure time [min] & $\begin{array}{c}\text { Splenic } \\
\text { preservation }\end{array}$ & $\begin{array}{c}\text { Diet resumption } \\
\text { [days] }\end{array}$ & $\begin{array}{c}\text { Drain removed } \\
\text { [days] }\end{array}$ & $\begin{array}{c}\text { Blood loss } \\
\text { [ml] }\end{array}$ & $\begin{array}{c}\text { Discharge } \\
\text { [days] }\end{array}$ \\
\hline 1 & 210 & Yes & 1 & 5 & 150 & 6 \\
\hline 2 & 225 & Yes & 1 & 4 & 250 & 5 \\
\hline 3 & 240 & No & 1 & 9 & 180 & 11 \\
\hline
\end{tabular}

the same trocar placement (Figure 1). During the procedure the surgeon was unable to dissect the cyst from the splenic vessels, so a distal pancreatectomy with splenectomy was performed. The Pfannenstiel incision was used to retrieve the specimen. The procedure lasted $240 \mathrm{~min}$. The drains were removed on day 9 due to an elevated amylase count in the draining fluid (over $10000 \mathrm{U} / \mathrm{l}$ ) - yet with a small volume of output as low as 30-40 ml/daily. The patient was discharged on day 13 . The histological examination defined the lesion as a mucinous cystadenoma.

Patient and procedure details along with outcomes are summarized in Tables I and II.

\section{Discussion}

Pancreatic cystic neoplasms are being incidentally diagnosed with higher frequency due to the wider availability of abdominal cross-section studies such as CT or magnetic resonance imaging (MRI). The prevalence of pancreatic cysts is about $2.5 \%$ of the population and increases with age, up to $10 \%$ of patients over 70 years old [2]. The World Health Organization (WHO) categorizes PCNs into four subgroups [3]:

- serous cystadenomas (SCAs),

- mucinous cystic neoplasms (MCNs),

- intraductal papillary mucinous neoplasms (IPMNs),

- solid pseudopapillary neoplasms (SPNs).

In every subgroup the WHO recognizes benign and malignant forms of PCNs. The most common PCNs are the IPMNs (38\%), MCNs (23\%), and SCAs (16\%) [4]. The initial diagnosis is based on cross-section imaging studies such as CT or MRI, with typical radiological qualities associated with every type of
PCN. Fine needle aspiration (FNA) guided by endosonography (EUS) allows cytological analysis and evaluates carcinoembryonic antigen (CEA) expression in the cyst. Higher CEA levels are found in the MCN and IPMN, while levels remain low in SCA $[2,5]$. This fact correlates with risk of malignancy, significantly higher with MCN (17\%) and main duct IPMN (45\%) compared with the risk as low as $1 \%$ in SCA [2]. Treatment options depend clearly on the possibility of malignancy. With SCA surgical treatment should be determined with presence of symptoms, while asymptomatic patients should be kept under surveillance. Surgical treatment of MCN and IPMN should be considered in every case, due to possible malignancy. The 2012 consensus guidelines provide specific and updated recommendations for surgical resection and surveillance for MCN and IPMN (Figure 2) [6].

The surgical treatment of PCN depends on the type of lesion, its localization, and possibility of malignancy. Small tumors with low risk of malignancy are treated with enucleation [4, 7]. Cysts with high risk, located monocentrically in the pancreatic head, require a Whipple pancreatoduodenectomy with or without the Traverso-Longmire pylorus-preserving technique. Whenever there is a doubt about the lesion's malignancy, a local lymph node dissection must be pursued [5]. However, the majority of PCNs occur in the body or tail of the pancreas [2]; therefore distal pancreatectomy is the most common procedure in such lesions. It can be performed either with open (ODP) or laparoscopic (LDP) technique (including SILS [8]). Minimally invasive techniques are associated with significantly lower blood loss, fewer blood transfusions, lower amounts of analgesics and 


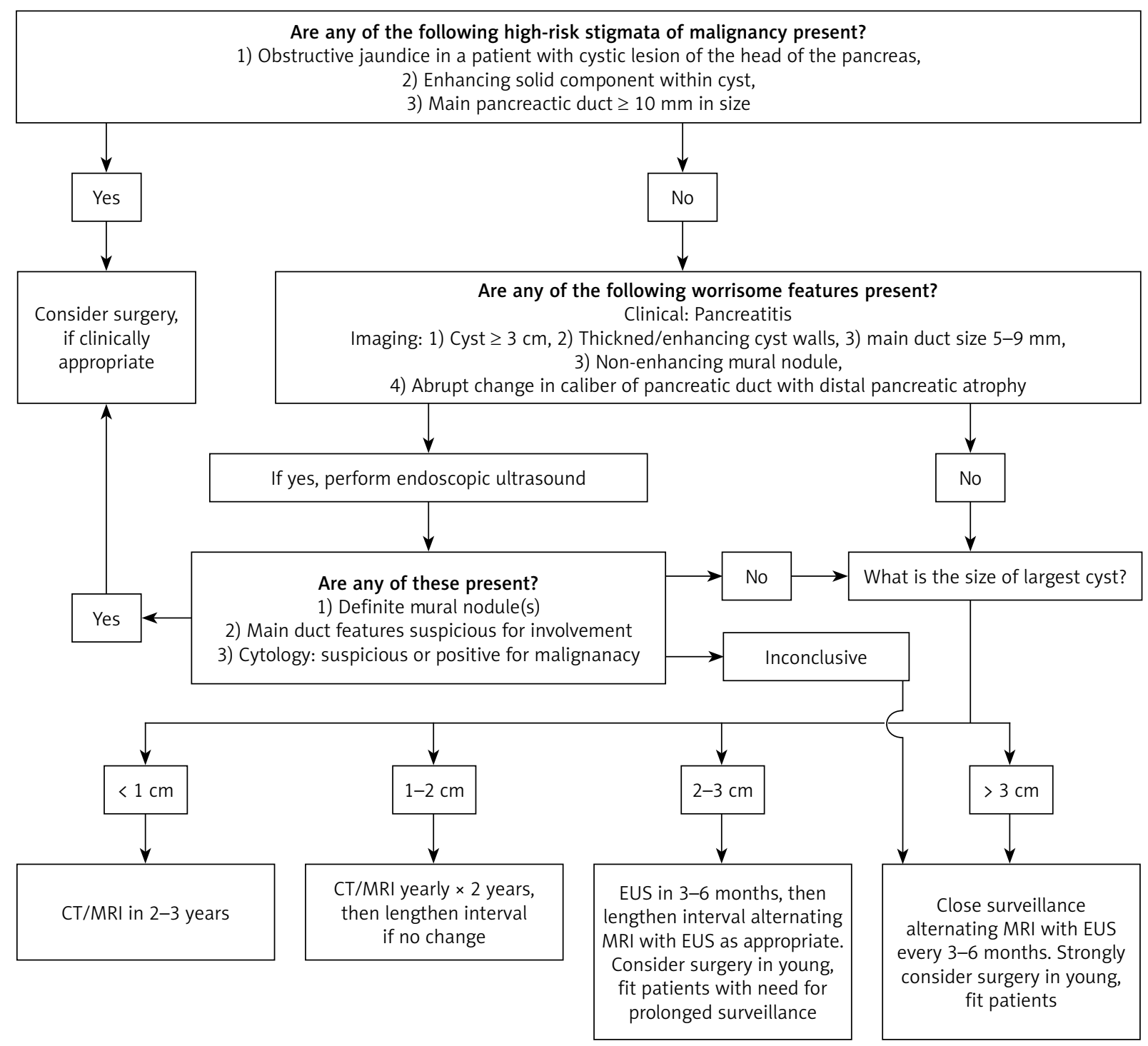

Figure 2. Algorithm for management of suspected BD-IPMN [6]

shorter hospital stay $[9,10]$. The morbidity is lower in laparoscopic procedures, whereas there are no significant differences in mortality or prevalence of postoperative pancreatic fistula. The conversion rate in LDP is reported as 9.5\% [9]. Kooby et al. performed an analysis comparing LDP and ODP for ductal adenocarcinoma. No significant differences were found in positive margin rates, number of nodes examined, or overall survival [11].

Distal pancreatectomy can be performed with or without preservation of the spleen. The higher rate of infectious complications after procedures with additional splenectomy favors, when possible, the choice of preservation technique [12]. It can be achieved with dissection of the splenic vessels or with Warshaw's technique (WT), during which the splenic artery and vein are ligated, yet the blood supply is maintained through short gastric and left gastroepiploic vessels [13]. When comparing the two preservation methods, $\mathrm{Yu}$ et al. in their meta-analysis noted a shorter procedure time with WT but did not find any difference in blood loss or complications. Patients who underwent WT however had higher gastric varices and splenic infarction rates, yet with no difference regarding reoperation and splenectomy [14]. Fernández-Cruz et al., describing minimally invasive preservation techniques, reported successful spleen salvage in $94.7 \%$ of LDP, and 
found WT to be faster and less technically demanding [15]. It is important to emphasize that there are no randomized controlled trials regarding the issue.

\section{Conclusions}

It is crucial to determine the type of pancreatic cystic neoplasm, while its possible malignancy may require surgical resection even if asymptomatic. The most frequent location of the lesion is the body and tail of the pancreas; therefore distal pancreatectomy is the most frequent surgical treatment. Minimally invasive techniques present certain advantages, favoring choosing LDP. Regarding spleen preservation techniques, there are no clear advantages of either procedure, yet it seems crucial to always consider preservation itself. The lack of randomized controlled trials regarding PCN and its surgical treatment necessitates further investigation of this matter.

\section{Conflict of interest}

The authors declare no conflict of interest.

\section{References}

1. Laffan TA, Horton KM, Klein AP, et al. Prevalence of unsuspected pancreatic cysts on MDCT. AJR Am J Roentgenol 2008; 191: 802-7.

2. Farrell JJ, Fernández-del Castillo C. Pancreatic cystic neoplasms: management and unanswered questions. Gastroenterology 2013; 144: 1303-15.

3. Zamboni G, Scarpa A, Bogina G, et al. Mucinous cystic tumors of the pancreas: clinicopathological features, prognosis, and relationship to other mucinous cystic tumors. Am I Surg Pathol 1999; 23: 410-22

4. Valsangkar NP, Morales-Oyarvide V, Thayer SP, et al. 851 resected cystic tumors of the pancreas: a 33-year experience at the Massachusetts General Hospital. Surgery 2012; 152: S4-12.

5. Testini M, Gurrado A, Lissidini G, et al. Management of mucinous cystic neoplasms of the pancreas. World I Gastroenterol 2010; 16: 5682-92.

6. Tanaka M, Fernández-Del Castillo C, Adsay V, et al. International consensus guidelines 2012 for the management of IPMN and MCN of the pancreas. Pancreatology 2012; 12: 183-97.

7. Costi R, Randone B, Mal F, et al. Laparoscopic minor pancreatic resections (enucleations/atypical resections). A long-term appraisal of a supposed mini-invasive approach. Videosurgery Miniinv 2013; 8: 117-29.

8. Michalik M, Bobowicz M, Lech P, et al. Distal pancreatic resection via laparo-endoscopic single site surgery - development of the technique. Videosurgery Miniinv 2010; 5: 142-5.

9. Jusoh AC, Ammori BJ. Laparoscopic versus open distal pancreatectomy: a systematic review of comparative studies. Surg Endosc 2012; 26: 904-13.
10. Lee MK, Vollmer CM. The current state of minimally invasive distal pancreatectomy. Curr Surg Reports 2013; 1: 106-13.

11. Kooby DA, Hawkins WG, Schmidt CM, et al. A multicenter analysis of distal pancreatectomy for adenocarcinoma: is laparoscopic resection appropriate? J Am Coll Surg 2010; 210: 779-85, 786-7.

12. Shoup M, Brennan MF, McWhite K, et al. The value of splenic preservation with distal pancreatectomy. Arch Surg 2002; 137: 164-8.

13. Warshaw AL. Conservation of the spleen with distal pancreatectomy. Arch Surg 1988; 123: 550-3.

14. Yu X, Li H, Jin C, et al. Splenic vessel preservation versus Warshaw's technique during spleen-preserving distal pancreatectomy: a meta-analysis and systematic review. Langenbecks Arch Surg 2015; 400: 183-91.

15. Fernández-Cruz L, Martínez I, Gilabert R, et al. Laparoscopic distal pancreatectomy combined with preservation of the spleen for cystic neoplasms of the pancreas. J Gastrointest Surg 2004; 8: 493-501.

Received: 6.07.2015, accepted: 28.07.2015. 